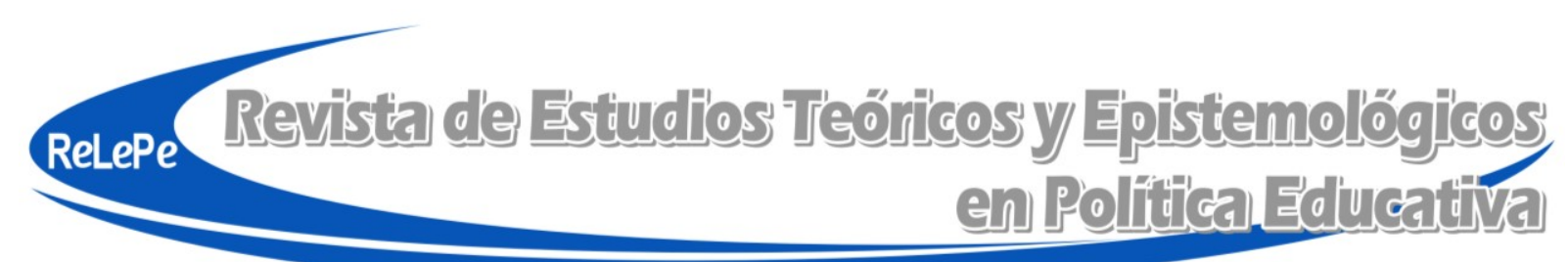

ISSN 2409-3696

DOI: $10.5212 /$ retepe.v.4.003

\title{
A política educacional e seus desafios na pesquisa: o caso do Brasil*
}

\author{
Nora Krawczyk \\ Universidade Estadual de Campinas \\ 3105nora@gmail.com
}

Resumo: Pesquisar política educacional e/ou políticas educacionais não é uma tarefa fácil, principalmente pela multiplicidade de disciplinas necessárias para seu estudo. Este artigo propõe oferecer alguns elementos de análise das tendências da pesquisa em política educacional nas últimas décadas no Brasil. Para isso, serão discutidos o campo da política educacional, o diálogo entre diferentes disciplinas, as diferentes abordagens, os temas e os contextos de produção.

Palavras-chave: Política educacional. Brasil. Historicidade.

\section{Education policy and its research challenges: the case of Brazil}

\begin{abstract}
Researching education policy and/or education policies is not an easy task, mainly because of the multiplicity of disciplines necessary for its/their study. This paper proposes to offer some elements of analysis of research trends in education policy in the last decades in Brazil. For that, the field of education policy, the dialogue between different disciplines, the different approaches, themes and contexts of production will be discussed.
\end{abstract}

Keywords: Education policy. Brazil. Historicity.

\section{La política educativa y sus desafíos en la investigación: el caso de Brasil}

Resumen: Investigar política educativa y/o políticas educativas no es una tarea fácil, principalmente, por la multiplicidad de disciplinas necesarias para su estudio. Este artículo propone ofrecer algunos elementos de análisis de las tendencias de la investigación en política educativa en las últimas décadas en Brasil. Para eso, serán discutidos el campo de la política educativa, el diálogo entre diferentes disciplinas, los diferentes enfoques, los temas y los contextos de producción.

Palavras clave: Política educativa. Brasil. Historicidad.

\footnotetext{
* Uma versão preliminar deste texto foi apresentada no V Encuentro Latino-americano de Metodologia em Ciências Sociais (ELMeCS), realizado em Mendoza, Argentina, em novembro de 2016. Mesa: "Desafios de la investigación educacional latino-americana a partir de um enfoque interdisciplinar".
} 


\section{Introdução}

Minha proposta aqui é oferecer elementos de análise das tendências da pesquisa em política educacional nas últimas décadas no Brasil. Para isso, serão discutidos o campo da política educacional, o diálogo entre diferentes disciplinas, as diferentes abordagens, os temas e os contextos de produção. Algumas questões aqui colocadas pretendem ser disparadores de um debate e oferecer diferentes possibilidades de compreensão do cenário atual de pesquisa em política educacional.

Quando nos referimos à política educacional, temos diante de nós dois campos de estudo: o da política e o da educação. Assim sendo, cabe perguntarmo-nos como definimos política e como definimos educação. Isso nos coloca uma questão importante e bastante controvertida: existe uma área de saber, de conhecimento, chamada educação, ou será que a educação é uma área de práticas e de políticas sobre as quais diferentes ciências humanas e sociais produzem conhecimento? Essas questões estão, de alguma forma, subjacentes aos modos de pensar a pesquisa em política educacional.

Outra questão no mesmo âmbito de compreensão do campo que estamos tratando de delimitar é a seguinte: estamos nos referindo à pesquisa em política educacional ou pesquisa das políticas educacionais? No primeiro caso, reconhecemos que existe um campo específico de pesquisa que é a Política Educacional, com maiúsculas, e que precisa de diferentes aportes disciplinares. No segundo, estudamos diferentes políticas educacionais, seus propósitos e suas consequências.

A maioria dos estudos tem focado em políticas educacionais determinadas. São poucos os que estudam a dinâmica política da produção de políticas educacionais, como um espaço de atividade, de relações de poder, de conflitos, etc. Desse modo:

- Por que e como surgem as prioridades em política educacional?

- Por que se produz uma política e não outra?

- Como se produz a política educacional?

Nesse caso, temos a educação compreendida como um processo social, uma prática social e, para ser compreendida na sua totalidade, precisa dos aportes de diferentes ciências e do diálogo entre elas. As fronteiras não são claras e, quando estudamos políticas educacionais, podemos conhecer, de alguma forma, os aspectos que destrincham a política educacional em uma determinada época, em um determinado lugar. Não podemos esquecer, também, que o êxito de um projeto educacional é multidimensional e não produto somente da política educacional. No entanto, esse é outro tema, mas não menos importante para a análise das políticas educacionais.

\section{O que estudamos nas pesquisas sobre políticas educacionais?}

A pesquisa sobre políticas educacionais tem diferentes abordagens, segundo a pergunta ou foco da pesquisa e, também, de acordo com sua intencionalidade: pode ser pesquisa sociológica, pode ser pesquisa econômica, pesquisa histórica, pesquisa antropológica, etc., de políticas educacionais. Por outro lado, pesquisas sobre outros temas que afetam à educação podem ajudar muito a compreender por que se implementam certas políticas e não outras, os efeitos "não esperados" que produz uma determinada política na dinâmica social e escolar, entre outros. 
Cada uma delas utiliza conceitos, categorias de análise, pressupostos e metodologias de seu campo. Elas trazem, portanto, aportes diferentes e, também, variações no interior de cada uma dessas disciplinas (clássicas ou contemporâneas; conservadoras ou críticas). Em alguns casos, não se parte do princípio epistemológico de que a educação é um processo social, uma prática social. Toma-se a educação como uma ação ou situação que pode ser analisada como qualquer outro fenômeno da sua disciplina. É o caso da economia clássica.

As referências empíricas hoje dominantes nas decisões políticas são oriundas, principalmente, do campo da economia clássica, inclusive para além das dimensões econômicas, produzindo proposições bastante reducionistas. Isso se explica no marco da reconfiguração da gestão pública e da busca da eficiência das políticas educacionais, da rentabilidade do investimento em educação, entre outros (MORDUCHOWICZ, 2003). Provoca, no senso comum, a confusão entre quantificar e explicar, ocultando o verdadeiro significado dos números (KRAWCZYK, 2013). "A economia foi se tornando uma disciplina imperialista que, pouco a pouco, iria invadindo a antropologia, a sociologia, as ciências políticas, etc." (BEAUD; DOSTALER, 1997 apud MORDUCHOWICZ, 2003, p. 27).

O reconhecimento científico de cada uma das disciplinas que hoje tem como uma das suas preocupações a educação e sua influência na definição e na legitimação de políticas educacionais é muito importante para compreender as próprias políticas educacionais, as quais divergem em momentos históricos distintos. Contudo, o diálogo com diferentes disciplinas também é influenciado pelas tradições acadêmicas nacionais. Constatamos, na pesquisa que realizamos sobre a Reforma Educativa na América Latina, que temos de levar em conta, quando lidamos com pesquisa em políticas educacionais, a relação entre a produção intelectual e a base social de onde emergem: os espaços institucionais onde se realizam as pesquisas, as categorias de análise (ainda que muitas vezes não explicitadas) e o "clima político". São dimensões interessantes que se destacam nas experiências de pesquisa em política educacional em cada um dos países (KRAWCZYK; VIEIRA, 2012).

No caso do Brasil, a pesquisa em política educacional foi bastante enriquecida no diálogo com as perspectivas críticas da administração escolar, principalmente no debate da democratização da gestão escolar e seu embate com as teorias da administração empresarial, contrapondo o discurso da democratização ao discurso da eficácia. A partir da década de 1980, a Sociologia da Educação incorpora outras dimensões de análise. Por outro lado, a institucionalização da pesquisa, conjuntamente à institucionalização da Pós-Graduação em Educação, diferentemente de outros países, trouxe como consequência uma forte associação entre atividades de formação (ensino) e de produção de conhecimento; e, principalmente, a burocratização do trabalho científico, o que reflete no que poderíamos denominar de "escolarização da produção científica" (CURY, 2004).

As especificidades nacionais alimentam os olhares dos pesquisadores e refletem, entre outras coisas, na escolha dos temas, na definição das categorias e dos pressupostos a partir dos quais as transformações serão analisadas. Não por isso esse olhar está livre da influência das tendências do debate regional e internacional.

\section{Diferentes abordagens no estudo das políticas educacionais}

Podemos dizer que quatro tipos de abordagem predominantes no estudo das políticas educacionais podem ser identificados: 
1) Abordagem descritiva, da qual, muitas vezes, resulta um registro de experiências "bem-sucedidas", considerando suficiente a mera descrição da realidade tal qual ela se manifesta ou por meio da opinião dos atores envolvidos. É uma abordagem bastante utilizada no Brasil pelas fundações e pelos institutos privados para legitimar certas propostas: políticas baseadas na evidência e pesquisa pragmática.

Segundo Barroso (2009), a política baseada na evidência constitui, muitas vezes, um modo de influenciar politicamente à pesquisa, não necessariamente por meio do financiamento e/ou pelos estudos encomendados, mas também por intermédio da agenda política, hierarquizando e validando certos temas e métodos de pesquisa. Essas pesquisas de tipo "pragmática" são, em muitos casos, registros de experiências "bem-sucedidas" em outros contextos regionais e/ou internacionais e que são consideradas plausíveis de serem transportáveis. Esse processo produz o que Barroso (2006) chama de "contaminação" entre países de conceitos, políticas e ações que traduzem uma convergência real com finalidades políticas mais vastas (BALL, 1998).

Podemos afirmar, então, que existe uma mutação na ideia de conhecimento ou, pelo menos, de conhecimento válido, que possui certo valor para a ação política. É aquele conhecimento produzido, em curto prazo, sujeito a uma agenda de problemas e/ou orientado pela demanda e com escasso conteúdo teórico e conceitual (DELVAUX, 2009; KRAWCZYK, 2014).

2) Abordagens qualitativas: As maiores dificuldades nesse tipo de abordagem são a possibilidade de identificar e construir analiticamente os processos de contradição e dialogar com a produção científica nacional e internacional, possibilitando sair do contexto particular do estudo em questão e da mera descrição da realidade tal qual se manifesta, para alcançar a compreensão do fenômeno na sua complexidade.

A literatura sobre o tema mostra-nos também a necessidade de uma formação sólida e domínio das técnicas, para a apropriação da realidade e para sua reconstrução. A riqueza da pesquisa qualitativa não está na possibilidade de aplicar seus resultados a locais e a sujeitos semelhantes (sentido convencional de generalização), mas em sua propriedade de criar conhecimentos (afirmações) universais sobre os processos sociais gerais (BOGDAN; BIKLEN, 1994). A pesquisa qualitativa tem se desenvolvido junto à desvalorização da pesquisa quantitativa, que levou à não análise de dados estatísticos (MARRADI; ARCHENTI; PIOVANI, 2007).

3) Avaliações de programas: muitas vezes respondem a demandas dos governos e, em outros casos, se confunde com análise de programas. Uma avaliação busca saber se os objetivos foram cumpridos ou não. Todavia, não pressupõe o questionamento do próprio programa: seus pressupostos, objetivos, etc. Também se confunde análise com demonstração.

4) Pesquisa comparada: ela pode cumprir diferentes funções: justificar opções ideológicas ou determinar "[...] viabilidades concretas que podem estar de maneira latente numa situação histórica". "Os processos associados a políticas concretas devem ser analisados em sua articulação dinâmica e não como simples situações produzidas por uma lógica de fatores encadeados, nenhum dos quais aparece afetado pelas exigências de especificidades históricas" (Zemelman em entrevista a KRAWCZYK; MORAES, 2003, p. 313).

A pesquisa comparada não é nova nas análises sobre a realidade educacional na região. Desde o século XIX, quando países latino-americanos iniciaram a criação de sistemas nacionais de educação, sua concepção acompanhou os princípios vigentes nos países hegemônicos. $\mathrm{Na}$ segunda metade do século XX, no bojo do processo de reconstrução internacional do capitalismo concebido no marco da teoria desenvolvimentista, a educação comparada (como disciplina) teve 
um extraordinário desenvolvimento, fornecendo subsídios para a formulação e a implementação de políticas de desenvolvimento educacional nos países periféricos (KRAWCZYK, 2013). Na América Latina, a pesquisa educacional crítica foi se afastando cada vez mais do enfoque comparativo em decorrência de sua forte associação com o paradigma positivista e com a política imperialista de desenvolvimento.

$\mathrm{Na}$ década de 1990, os estudos comparados em Educação tomam maior fôlego, principalmente nas áreas de política educacional. Os estudos surgem, em um primeiro momento, encomendados e divulgados pelos Órgãos Internacionais com um caráter meramente descritivo, em busca de justificar as opções ideológicas e uma padronização das políticas na região.

Os estudos comparados também vêm sendo incentivados para a compreensão de processos educacionais que atravessam as fronteiras dos Estados e/ou das nações. No entanto, muitas vezes, pela ausência de uma pergunta de pesquisa que justifique a comparação e/ou pelo pouco conhecimento dos países analisados, a pesquisa acaba se reduzindo à constatação de convergências entre as situações nacionais.

O potencial da pesquisa comparada está, a nosso ver, no potencial de interpretação das convergências e das especificidades na concretização de políticas globais a partir da historicidade dos fenômenos contemporâneos. Para isso, é necessária uma perspectiva histórico-sociológica (ou sócio-histórica) que permita compreender a historicidade dos processos constitutivos da relação entre as forças políticas, econômicas e sociais que realizam a dinâmica de construção, de desconstrução e de reconstrução das conexões estabelecidas nas conjunturas nacionais e internacionais (PIOVANI; KRAWCZYK, 2016). É a passagem da análise dos fatos para a análise do "sentido histórico dos fatos" (NÓVOA, 1995).

\section{Importância da dimensão histórica no estudo da política educacional e das políticas educacionais}

Ainda pouco se leva em conta a historicidade dos processos políticos educacionais. Naturalizam-se conceitos por não explicitarem a historicidade que eles carregam. A possibilidade de recuperar a historicidade nas propostas político-educacionais e nas realidades concretizadas, tanto nos estudos qualitativos quanto nos estudos comparados, poderia colaborar com a construção de uma perspectiva teórico-metodológica para análise dos processos sociais de construção da política educacional - desafio que parece ainda não termos dado conta.

A naturalização dos conceitos aprisiona a produção de novos conhecimentos porque, muitas vezes, ela orienta a "visão" do pesquisador e produz cegueira de novos processos sociais em curso, impedindo criar outros conceitos e categorias de análise que a expliquem na sua realidade concreta.

O uso dos conceitos exige ser historicizado. Os conceitos são objeto de problematização para determinar sua especificidade. Não se trata de "provar" um conceito, mas de descobrir sua especificidade. Os conceitos não buscam garantias de que seu conteúdo se contraste com determinadas estruturas reais; mas de que o conteúdo seja determinável segundo a exigência de especificidade crescente, que transformará o conteúdo do conceito. (Zemelman em entrevista realizada por KRAWCZYK; MORAES, 2003, p. 314). 


\section{O conhecimento como dimensão de regulação}

Com a reconfiguração da relação Estado-sociedade-mercado, produzida a partir da década de 1980, na maioria dos países ocidentais, multiplicam-se os atores que mobilizam o conhecimento para agirem no plano político, e esse conhecimento tornou-se um instrumento importante para a tomada de decisões político-educativas. Os governos e as agências supranacionais os utilizam cada vez mais para justificar suas propostas e suas opções. Assim, “[...] as próprias políticas públicas põem em prática dispositivos de regulação baseados na difusão de conhecimentos" (DELVAUX, 2009, p. 960). Segundo Barroso (2009), a capitalização dos conhecimentos - informação estatística, pesquisas avaliativas, indicadores de resultados, identificação de boas práticas, etc. -, na política, é mais simbólica do que real.

É possível afirmar que a ideia de conhecimento invocado no processo político não somente sofreu uma mutação como também foi se alargando na sua trajetória de interação com as políticas públicas na ação pública. Nesse sentido, designa-se conhecimento "[...] para tudo o que pretende dizer o real e é transmitido por meio de linguagem oral, escrita (textos, quadros estatísticos,...), ou iconográfica (gráficos, fotografias, desenhos, filmes...)" (DELVAUX, 2009, p. 962). As fontes, os dados e o conteúdo de conhecimento são escolhidos fortemente condicionados por interesses e por lógicas de poder (BARROSO, 2009).

A produção e a circulação de conhecimento vão outorgar, aos diferentes atores, maior ou menor poder de regulação segundo os interesses em jogo. É o caso, por exemplo, da União Europeia que, por meio do Programa Internacional de Avaliação de Alunos (PISA), oferece uma comparação internacional de rendimento e de outras informações complementares das populações escolarizadas de cada um dos países, o qual tem se tornado cada vez mais uma referência importante não só para a definição de política educacional nacional como também como indicador de comparação do desenvolvimento e "capital" humano nos diferentes países, agindo, também, no espaço da política econômica internacional (CARVALHO, 2011). No caso do Brasil, encontramos, por exemplo, uma multiplicidade e uma superposição de sistemas de avaliação de resultados, pelos quais os governos municipais, estaduais e nacional competem pela sua circulação e pelo seu uso.

A reconfiguração do que é conhecimento válido e o lugar que esse conhecimento tem assumido nas últimas décadas na tomada de decisões político-educacionais colocam-nos como pesquisadores frente a uma situação bastante complexa.

\section{Desafios atuais para a pesquisa em educação}

$\mathrm{Na}$ última década, o Estado brasileiro assumiu a responsabilidade pela universalidade, obrigatoriedade e gratuidade do ensino básico. São muitos e complexos os desafios que envolvem essa responsabilidade frente a uma realidade educacional que expressa uma enorme dívida social e requer uma atuação agressiva do poder público para atender, em curto prazo, não somente às demandas locais, mas também às exigências internacionais. Iniciou-se um conjunto de políticas que tem procurado o aumento da matrícula e a retenção e o êxito dos estudantes, e outras que afetam as relações de poder na organização e na gestão do sistema educacional e no trabalho pedagógico nas escolas. Afetam, também, as trajetórias escolares e as condições de trabalho docente.

Após, aproximadamente, duas décadas de debate e de pressões sociais pela construção de uma educação brasileira mais inclusiva, encontramo-nos, neste momento, em um processo regressivo no âmbito das políticas sociais que, sem dúvida, afetam a realidade educacional de uma 
forma bastante importante e preocupante. Estamos diante de um processo regressivo de inclusão educacional que, ao mesmo tempo e implicitamente, reforça a segregação escolar e a desigualdade de oportunidades da sociedade, correndo-se o risco de, por meio de velhos caminhos, criar novos procedimentos de seleção. Nesse sentido, junto aos desafios na pesquisa em educação, nos próximos anos, está o compromisso pela construção de um conhecimento que desvende os mecanismos de reprodução das desigualdades sociais na sociedade brasileira.

Para finalizar, gostaríamos de destacar alguns dos desafios da pesquisa em política educacional:

1) Revigorar o debate teórico e histórico. A pesquisa empírica é fundamental para o conhecimento aprofundado da realidade, mas, para poder organizar e analisar os dados coletados, é necessária uma direção que permita interpretar os aspectos singulares da realidade observada e integrar as pesquisas no todo maior da produção científica. A preocupação com as dimensões teóricas e históricas possibilitará à pesquisa interpelar as políticas educacionais e a realidade educacional concretizada como processos que carregam historicidade. Dessa forma, é possível colaborar com a desnaturalização das categorias de análise, identificando os espaços de continuidade e de ruptura e superando o limite da inevitabilidade, tão pernicioso para a produção científica.

2) Articular as diferentes áreas e as abordagens das pesquisas em política educacional. $O$ fortalecimento do debate entre os pesquisadores para discutir os resultados de suas pesquisas e mais diálogo entre as produções com diferentes enfoques metodológicos ajudarão a criar um ambiente coletivo de produção científica e otimizar a área de política educacional.

3) Repensar a formação do pesquisador em política educacional.

4) Não se render às demandas imediatistas nem às ansiedades para encontrar respostas rápidas e "mágicas". Isso não quer dizer que não devamos levar em conta os problemas concretos que surgem no cotidiano da educação, mas a pesquisa não pode estar a serviço de solucionar pequenos impasses do cotidiano. O tempo de maturação do processo de construção de conhecimento (individual e coletivo) não é o mesmo que o das decisões políticas, o das necessidades dos professores e o dos gestores da educação.

5) Assumir a tensão entre o campo acadêmico e o campo de atuação política, fronteira bastante sensível na área de política educacional. Produzir conhecimento novo e socialmente significativo, que incorpore uma reflexão, em uma perspectiva em médio e longo prazo e que não exclua alguns assuntos sob o argumento da inevitabilidade de algumas situações.

6) Repensar a divulgação da produção, dos resultados de pesquisa. Divulgar não é o mesmo que publicar. Pouco diálogo com a sociedade, ausência de explicitação metodológica, pouco debate escrito.

7) Promover um diálogo entre conhecimento social crítico e a ação política na educação (o que significa debater questões complexas, em uma arena cheia de conflitos e tensões) é uma forma promissora de contribuir com o processo de democratização da educação. Devemos enfrentar o desafio por meio de uma postura interdisciplinar do estudo das políticas educacionais, de contrapormos a visão economicista da educação a uma visão "da evidência". 
A política educacional e seus desafios na pesquisa: o caso do Brasil

\section{Referências}

BALL, S. Big polices/small world: an introduction to international perspectives in education policy. Comparative Education, v. 34, n. 2, p. 119-130, 1998. DOI: https://doi.org/10.1080/03050069828225

BARROSO, J. A utilização do conhecimento em política: o caso da gestão escolar em Portugal. Educação \& Sociedade, Campinas, v. 30, n. 109, set./dez. 2009. DOI: https://doi.org/10.1590/s0101-73302009000400004

BARROSO, J. O Estado e a Educação: a regulação transnacional, a regulação nacional e a regulação local. In: BARROSO, J.; VISEU, S. (Orgs). A regulação das políticas públicas de Educação: espaços, dinâmicas e actores. Lisboa: Educa/Unidade de I\&D de Ciências da Educação, 2006. p. 41-70.

BOGDAN, R.; BIKLEN, S. Investigação qualitativa em educação: uma introdução à teoria e aos métodos. Porto: Porto Editora, 1994.

CARVALHO, L. M. O PISA como dispositivo de conhecimento \& política. In: CARVALHO, L. M. (Org.). O espelho do perito. Inquéritos internacionais, conhecimento e política em educação: o caso do PISA. Lisboa: Fundação Manuel Leão, 2011. p. 11-40.

CURY, C. R. J. Graduação/Pós-Graduação: a busca de uma relação virtuosa. Educação \& Sociedade, Campinas, v. 25, n. 88, p. 777-793, out. 2004. DOI: https://doi.org/10.1590/s010173302004000300007

DELVAUX, B. Qual é o papel do conhecimento na acção pública? Educação \& Sociedade, Campinas, v. 30, n. 109, set./dez. 2009. DOI: https://doi.org/10.1590/s0101$\underline{73302009000400003}$

KRAWCZYK, N. Conhecimento crítico e política educacional: um diálogo difícil, mas necessário. In: KRAWCZYK, N. (Org.). Sociologia do Ensino Médio: crítica ao economicismo na política educacional. São Paulo: Cortez, 2014. p. 13-32.

KRAWCZYK, N. Pesquisa comparada em educação na América Latina: situações e perspectiva. Educação Unisino, São Paulo, v. 17, n. 3, p. 199-204, set./dez. 2013. DOI: https://doi.org/10.4013/edu.2013.173.03

KRAWCZYK, N.; MORAES, R. C. C de. Estudos comparados, projeto histórico e análise de políticas públicas. Entrevista com Hugo Zemelman. Educação \& Sociedade, Campinas, v. 24, n. 82, p. 311-320, abr. 2003. DOI: https://doi.org/10.1590/s0101-73302003000100022

KRAWCZYK, N.; VIEIRA V. L. Uma perspectiva histórico-sociológica da Reforma Educacional na América Latina: Argentina, Brasil, Chile e México nos anos 1990. Brasilia: Liberlivro, 2012.

MARRADI, A.; ARCHENTI, N.; PIOVANI, J. Metodología de las Ciencias Sociales. Buenos Aires: Emecé, 2007.

MORDUCHOWICZ, A. Discusiones de economia de la educación. Buenos Aires: Losada, 2003.

NÓVOA, A. "Modelos de análise em educação comparada: o campo e a carta". Tradução do artigo publicado na revista Les Sciences de l'education pour l'ère nouvelle, n. 2-3, 1995. 
PIOVANI, J. I.; KRAWCZYK, N. Los Estudios comparativos: algunas notas históricas, epistemológicas e metodológicas. Educação \& Realidade, Porto Alegre, v. 42, n. 3, p. 821-840, jul./set. 2016. DOI: https://doi.org/10.1590/2175-623667609

Recebido em 20/08/2018

Versão corrigida recebida em 03/01/2019

Aceito em 10/01/2019

Publicado online em 21/01/2019

\begin{tabular}{l}
\hline Nora Krawczyk \\
Doutora em Educação pela Universidade Estadual de Campinas (1992) e Pós-Doutorado pela Maryland \\
University (EUA) (2016). Professora da Faculdade de Educação da Unicamp. \\
\hline
\end{tabular}

